\title{
The Challenges and Coping of Internet Financial
}

\author{
Penghu Wang \\ School of Business \& Management, Donghua University, Shanghai, China
}

\begin{abstract}
Internet financial is a new financial model combining the Internet and finance. With the Internet and big data technology, the Internet companies can reduce the cost of financial transactions, changing information asymmetries, and expanding the geography and time of financial transactions. The article will focus on banking, analyzing the impact of the Internet financial on traditional finance and the advantages and disadvantages of Internet companies and financial institutions respectively, and build the three modes of the commercial banks to deal with Internet financial challenges.
\end{abstract}

Keywords - e-commerce finance, internet financial, financial disintermediation, transaction costs

\section{互联网金融的挑战与应对}

\author{
王鹏虎 \\ 东华大学旭日管理学院, 上海, 中国
}

摘 要 互联网金融是互联网和金融相结合的新型金融模式。借助互联网和大数据技术, 互联网企业可以降低金融交易成本, 改 变信息不对称现象, 扩大金融交易地域和时间。本文将以银行业为重点, 分析互联网金融对传统金融的影响, 并针对互联网企业与金 融机构各自优势劣势的分析, 构建商业银行应对互联网金融挑战的三种模式。

关键词 电商金融, 互联网金融, 金融脱媒, 交易成本

随着计算机和互联网技术的发展, 其对社会经济各领 域的影响正在逐步深化。银行业作为现代经济的重要核心 产业, 也正在经历着互联网深刻的影响。同时, 一些互联 网企业也依托互联网技术逐步渗透到金融服务领域, 形成 对传统金融的冲击和挑战。本文重点分析互联网金融对传 统金融的挑战, 并针对互联网企业与金融机构各自优势劣 势的分析, 构建商业银行应对互联网金融挑战的三种模式。

\section{1. 互联网企业对传统金融的冲击}

传统金融机构存在的基础是金融中介理论。从早期的 交易成本和信息不对称, 到现代的金融中介功能观、风险 管理、参与成本和价值创造等方面的理论研究, 都表明了 金融中介存在的必要性。互联网金融对传统金融的冲击主 要是在互联网技术进步推动下, 金融活动的交易成本大大 下降, 信息获取和处理更加方便快捷, 信息不对称现象发 生根本改变, 一些互联网企业在一定程度上承担了传统金 融机构的职能, 形成了对传统金融机构的冲击。互联网金 融可能成为不同于商业银行间接融资、也不同于资本市场 直接融资的第三种金融融资模式。

C 2014. The authors - Published by Atlantis Press

\section{1 互联网金融的渗透领域}

互联网金融对传统金融领域进行渗透, 首先是支付, 接着是贷款和理财, 最后是存款。近期以阿里集团为代表 的互联网企业已经开始渗透活期储蓄存款。此外, 还有一 些边缘性的业务, 如说供应链金融、保理等。此外还有对 银行业意外的其他金融行业的渗透, 如网上证券, 网上保 险等等。

\section{2 互联网金融典型案例}

从电商领域渗透的阿里巴巴。阿里的支付宝本来是为 淘宝网解决支付问题的, 但是目前支付宝已经成为最重要 的第三方支付机构, 服务领域渗透到更多的小额支付领域; 阿里小贷 2013 年年累放贷款一千多亿元, 服务了七十多万 客户; 余额宝截止到 2014 年 3 月已经达到 5000 多亿元; 淘宝网上已经有三十多家基金公司入驻; 阿里也在申请设 立银行，成为首批民营银行的试点企业。

从网络社交领域渗透的腾讯。最近腾讯的动作很频繁, 除了早期的三马合作网上卖保险, 近期更是从微信开始切 入支付和理财, 同时腾讯也在和银行合作发行网络信用卡, 
并且也获得了设立银行的资格。

还有从传统商业领域进军电商进而渗透金融领域的苏 宁。苏宁原来是线下连锁商业企业, 2010 年提出转型电商 的发展战略, 目前从电商领域入手, 开始拓展金融业务, 成立了小额贷款公司、保险销售公司和第三方支付公司, 并提出设立银行的申请。

其他的案例还有从搜索切入的百度, 从新闻门户进来 的新浪等等。我们看到各类互联网企业, 无论是搜索、社 交、新闻还是视频门户, 都在抢互联网金融的入口, 通过 自己的核心互联网应用切入客户的金融需求。

\section{3 更多 IT 企业在做 P2P 和众筹融资}

现在 P2P（Peer to peer）和众筹融资（Crowd funding） 成为互联网金融的又一热点领域。美国在 2012 年 3 月颁布 了《初创期企业推动法案》 (jobs Act), 给美国的 P2P 一个 正式的合法身份, 到 2012 年底, 美国的众筹融资网站有 700 多家。

目前在中国的 P2P 和众筹融资平台大概有一千家, 发 展很快, 目前这个领域没有监管, 也没有准确的数据统计。 但是随着客户数量的增长, 其潜在的金融风险值得关注。

\section{4 余额宝的实质及其对银行存款的冲击}

最近大家关注比较多的是以余额宝为代表的互联网理 财产品, 这些产品已经切入到银行最核心的业务领域一存 款, 虽然没有直接去吸收存款, 而是通过支付宝钱包、微 信等手机客户端绑定客户银行卡, 再对接一些货币基金来 为客户提供资产收益, 但是银行的一些储蓄存款的确被分 流了。根据央行一月份的数据, 银行的人民币存款减少 9402 亿元, 其中相当数量的存款是被 “宝宝们” 吸走, 变成不 计入一般性存款的同业存款了。

余额宝本质上只是一个销售前端的整合, 后面的资产 端并没有什么变化, 就是货币基金存放银行同业存款。存 款转了一圈又回到银行, 但是发生了两个变化: 第一, 资 金的性质变了, 从活期储蓄存款变成了同业存款; 第二, 银行负担的成本变了, 从 $0.385 \%$ 到了随行就市的同业存款 利率, 客户资金最终收益来源还是银行。

互联网企业通过获得小额贷款、担保和第三方支付等 金融牌照以及在无牌照的情况下通过搭建互联网平台提供 金融中介服务已成为金融市场的一个新的现象, 并形成了 与传统金融形态迥异的业务模式。在互联网金融模式下, 现在金融业的分工和专业化被大大淡化了, 被互联网及其 相关软件替代了; 市场参与者更加大众化, 互联网金融交 易所引致出的巨大效益更加普惠于普通老百姓。这是一种 更为民主化，而不是少数专业精英控制的金融模式。

\section{2. 互联网企业与金融机构的优劣势及竞合关系}

互联网企业对银行业金融机构传统业务的渗透、冲击 和挑战是深刻而剧烈的, 必然会分流银行业的部分客户和 业务, 迫使银行业做出更大的改变。对于互联网企业的挑 战, 银行应有充分、深刻而全面的认识。另一方面, 互联 网企业自身也有其劣势和局限性, 也不可能对银行传统业 务造成根本性致命性冲击, 更无法颠覆和替代银行业。应 该客观地、理性地、辩证地看待互联网企业和银行的优劣 势。

（一）互联网企业的优势

1.没有监管的限制是互联网企业最重要的优势。在资 本金、资产负债比例、业务准入、安全、客户信息保护等 诸多方面, 互联网企业都没有受到像银行一样的监管, 可 以获得比银行大得多的创新和发展的空间。

2. 具有创新的动能。互联网的快速发展, 要求企业必 须不断的创新, 否则就被淘汰。互联网企业多数是民营企 业, 这些企业更具备危机意识和创新能力, 能够更好适应 互联网的发展。

3.互联网企业非常注重客户体验。互联网企业对体验 的重视度高于安全, 甚至可以把客户体验放在第一位, 而 客户体验正是网络用户最为关注和重视的, 没有优秀的用 户体验, 就无法吸引客户, 无法成为导流入口。由于互联 网企业没有银行的物理网点优势, 因此其网站和客户端等 导流入口就显得非常重要, 互联网企业会倾其全力做好客 户体验, 甚至一定程度上牺牲安全。

4. 互联网企业没有历史负担。互联网企业本来就没有 金融业务的收入, 可以把导流进来做金融获得的收益返还 给客户, 甚至还可以把其自身其他收入贴补给客户, 因此 占据了一个道德上的高地。相比之下银行本身的收入来源 就是利差收入和服务收费, 原来已经获得的收益难以重新 分配。

\section{（二）互联网企业的劣势}

1.没有金融牌照，不受监管，当然也不受保护，业务 风险和客户损失没有救护机制。

2. 无法对接有效的金融资产，最终给客户提供的收益 是无法完全掌控的, 还得依靠传统金融机构的基础资产。

3. 安全程度比较低。技术安全和资金安全的保障都比 较低, 并非技术上做不到, 而是因为把体验放到了第一位, 一定程度上牺牲了安全。

4.流动性管理方面没有经历过考验。

（三）金融机构的优势与劣势

金融机构跟互联网企业正好是完全颠倒, 金融机构的 优势就是互联网企业的劣势, 反之亦然。金融机构有合法 的金融牌照, 受法律的保护; 有严格的风险管理, 尤其是 
流动性管理; 注重安全和声誉, 拥有大量客户的信任; 具 有非常完整的产品线, 特别是高度依赖于风险管理技术的 资产业务。风险管理从一开始就是银行等金融中介的核心 功能, 只不过在金融创新的今天显得更加重要了 (Scholtens \&Wensveen, 2000)。金融机构通过风险管理技术, 可以为 客户提供产生现金流的资产, 所以互联网企业最后还得依 靠金融机构提供生息资产。

金融机构的劣势恰恰是互联网企业的优势。金融机构 受到了严格的监管限制, 缺乏创新的强大动力, 对市场的 反应比较慢, 不灵活, 对客户体验的重视不够, 还有历史 负担和既得利益对银行的束缚。

（四）互联网金融的局限性

互联网拥有强大的通讯与交互功能, 是一种巨大的变 革力量, 尤其对银行销售和客户服务渠道的改变以及对银 行与客户交互方式的改变, 绝对是革命性的, 它可以把很 多中介去掉, 降低交易成本, 提高服务效率, 优化客户体 验, 扩展服务时间和范围, 实现普惠金融, 这是互联网非 常强大的一方面。

但是同时我们也应该认识到互联网金融的局限性。互 联网金融只是互联网在金融领域的一种应用, 会改变传统 金融的一些方式方法, 但不应该是颠覆和替代。未来不是 互联网企业变成金融机构, 而是金融机构会变成互联网企 业, 变成越来越多的依托互联网开展业务的现代服务企业。 金融机构会积极运用互联网技术先进的成果, 成为信息化 浪潮的积极参与者和推动者。

陈志武教授在《互联网金融到底有多新？》一文中重 点论述了互联网金融的局限性, 认为 “互联网金融不是新 金融, 而只是金融销售渠道、金融获取渠道意义上的创新。 换言之, 互联网在渠道意义上挑战传统的银行和资本市场, 但在产品结构和产品设计上跟银行、保险、资本市场等所 经营的产品没有区别。金融的本质没变, 还是交易各方的 跨期价值交换, 是信用的交换。互联网的出现, 改变了金 融交易的范围、人数、金额和环境, 但没有改变金融交易 的本质。”

\section{（五）互联网企业与金融机构的竞合关系}

金融机构和互联网企业不是你死我活的替代关系，应 该是竞合关系, 竞争是一定存在的, 有相互的渗透与反渗 透, 但是也有广阔的合作空间。

银行拥有全面的资产、负债、中间业务, 互联网企业 更擅长支付服务和吸收负债, 而资产业务不占优势; 从批 发和零售维度划分, 互联网企业在零售领域具有强大的优 势, 而批发领域需要的资金量巨大, 更需要一种安全和信 誉, 所以 B2B 领域仍然是传统银行非常有优势的领域。银 行和互联网企业在竞争的同时, 也存在着巨大的合作空间,
例如可以把互联网企业变成金融机构的前端, 变成销售渠 道, 让它去导流, 去完成社会闲散资金的聚集和小额支付; 而银行在后端专心做资产业务, 特别是大中型公司金融。 互联网企业与金融机构各自发挥自己的优势, 在各自擅长 的市场开展业务, 并且在交叉客户和业务领域开展合作, 构建一个和谐的金融生态环境。

\section{3. 银行应对金融互联网的三种模式}

现在银行面临外部经营环境的巨变，资本监管、金融 脱媒、利率市场化和互联网技术进步, 这四大趋势都使银 行业受到巨大挑战, 所有这些趋势, 都指向一条, 就是银 行必须走轻资本低费用的集约化发展道路。

金融中介业存在的原因在于交易成本，金融中介降低 交易成本的主要方法是利用技术上的规模经济和范围经济, 随着交易量的增加, 单位产品的运营成本就会降低。金融中 介存在的另外一个理由是信息不对称及其造成的逆向选择 和道德风险(Benston 和 Smith, 1976)。

由于信息技术和因特网的广泛应用,人们可以更多地 获得信息, 降低了逆向选择和道德风险。原来那些从交易 成本和信息不对称的角度来解释金融中介存在的原因开始 受到了质疑。默顿与博迪 (Merton\&Bodie,1993) 认为金融 结构并不重要, 重要的是金融体系的功能。

随着金融市场组织制度的变化和信息技术的进步, 金 融中介的脱媒一直在发展和深化。脱媒有两种具体形态, 一种是金融脱媒, 一种是技术脱媒。金融脱媒是大型客户 的金融活动摆脱了银行间接融资中介作用, 成为依托资本 市场和非银行金融机构的直接金融; 技术脱媒则是小微企 业和个人客户的金融活动彻底脱离了所有金融中介, 直接 通过互联网平台来开展。通过互联网, 交易双方可以极大 程度的降低信息收集成本, 解决信息不对称的问题, 进而 增加交易机会和降低交易成本。

为了积极应对互联网带来的金融去中介化, 银行就必 须大力发展互联网金融, 积极应对脱媒造成的影响。从目 前我国银行的实践来看, 主要有下三种模式: 第一是金融 产品的互联网销售, 即网络银行的发展道路, 从电子银行 到现在的直销银行, 再到未来银行; 第二是银行自办电商, 亦商亦融; 第三是社会的电商, 银行的服务, 即银行与互 联网企业尤其是电商企业的合作模式。

\section{(一) 电子银行模式}

中国银行业的网络银行已经走过了十几年的发展历 程, 从第一代网银的信息上网到第二代网银的产品上网, 再到现在第三代网银的服务上网, 基本实现了产品销售和 客户服务的网络化。现在很多银行都推出了第三代网银, 比如招商银行的 “ $\mathrm{i}$ 理财”、中信银行的金融商城、光大银 
行的阳光营业厅等。

第三代网银是银行服务上网, 秉承以人为本和以客户 为中心的理念, 关注客户数据, 把客户的行为、交易记录、 甚至客户在其他网站的信息收集起来, 进行数据挖掘, 然 后进行精准的定向营销。同时把银行的客户经理、理财经 理配置到互联网上。在初期的网络银行上, 客户是单向的、 自助式上网办理业务, 在第三代网银上, 客户与银行是双 向的交互, 售前营销咨询、售中业务办理、售后服务投诉 处理都可以在互联网上实现。

同时银行也在依托物理网点, 引导客户开立和使用网 上银行, 把线上的网银和线下的网点进行结合, 即 $\mathrm{O} 2 \mathrm{O}$ 模 式。近期有些银行在居民区开设了一些社区银行, 社区银 行应该定位于通过社区银行的触角把线下客户转化为线上 客户，而不是现有物理网点的扩充或轻型化。

\section{（二）银行自办电商模式}

第二种模式即银行自办电商, 自己做 B2C 或 B2B 电子 商务平台, 给客户提供线上交易服务, 沿着交易往后延伸 到支付和融资的金融服务。近期很多银行都在做电商, 这 是目前国内银行业出现的新趋势, 比如建行的“善融商城”、 交行的 “交博汇” 和工行的 “融 $\mathrm{e}$ 购” 等, 这些都是以银 行部门为主体的运作模式。民生电商则是在银行股东层面 成立专业的电商公司来运作的模式, 未来也许会出现由银 行成立控股子公司来作为运作主体的模式。

银行是否应该做电商存在很大争论。支持方认为银行 有能力做, 而且通过自办电商可以获取客户真实交易数据, 然后为客户提供在线支付和融资等增值服务, 提高客户黏 性。但是反对方认为银行开办电商业务不符合社会化分工 原则, 也没有相应的法律支持, 而且银行没有盈利模式, 甚至有人认为银行没有互联网基因。

至于到底应不应该做, 我认为只能留待实践来检验, 目前通过几家银行的运作情况来看, 客户数、交易量和客 户活跃度情况都不是很理想。

（三）社会电商金融服务模式

银行的互联网业务离不开社会电子商务的发展, 同时 银行也是社会电子商务的有机组成部分。银行作为专业的 金融服务提供商, 和社会上众多的电商开展广泛合作, 为 它们提供金融服务。电子商务是商流、信息流、资金流、 物流四流合一, 其中非常重要的资金流, 就需要银行来做, 通过提供在线支付和在线融资, 为社会电商服务。银行既 是电子商务重要的实践者, 也是创新的推动者, 还是整个 社会电商的环境的支撑者。整个电子商务四流合一银行是 最终实现电子商务闭环不可缺少的一个节点, 主要发挥四 方面的作用, 即信用中介、支付中介、资金中介、信息中 介。
银行在为社会电商服务过程中又逐步形成三种模式: 第一是监管模式, 所有电商平台上的客户账户和资金放在 银行, 银行管资金, 平台管交易, 电商平台接触不到客户 的资金。这种方式对银行来讲, 控制力最强, 收益也最大; 第二种是存管模式, 银行管客户的电子台账, 同时也有客 户的实体账, 交易平台也管客户的资金账户，双方每天进 行日中对账。这种模式下往往是几家银行对接一个电商平 台, 是一对多的关系; 第三种是支付网关模式, 或者叫第 三方支付模式, 电商平台有一个账户体系, 以此为基准, 然后去对接各家银行的网关, 客户在交易过程中需要支付 时调用银行的网关。这种模式银行最被动, 没有任何控制 力, 而且收益也是最差的。当然, 这三种模式现在银行都 得去做, 以适应不同的电商平台及其客户的业务需求。

在线融资是目前电商金融服务的一个热点和难点, 在 这方面最难的并不在于银行本身的产品创新, 而是在于如 何把交易平台、物流仓储、第三方的价格等等一些数据信 息整合在一起。很多信息不是银行的, 银行必须在线获得 客户的交易信息、物流仓储信息和价格信息, 然后在线签 订电子质押合同，实现货物的质押和赎放货等等。这些业 务处理更多是资源整合上的难度, 而不是技术上的难度。 目前在线融资多数是需要部分流程线下处理的, 授信和提 款的申请线上提交，授信和放款的审核是银行线下处理。 最近也有部分银行实现了全流程不落地秒级的在线融资, 其背后的具体模式又可分为保证担保、抵押和质押三种方 式, 其中电子商务平台和客户最需要的在线货押融资也已 经在部分银行上线, 正在进行实践运用。

\section{参考文献(References)}

[1] Daqiang Yang.The trends and frontier of the financial intermediation theory. Jinan Finance, 2007 (12):24-27

[2] Ping Xie, Zhuanwei Zou. The study on internet financial model. Financial Research, 2012 (12):11-22

[3] Benhua Xiao. The development of the U.S. public to raise financing model and its enlightenment to China. International Finance, 2013 (1):52-56

[4] Penghu Wang, Lianze Zhang, Liangfang Li. B2B e-commerce: the leading business growth engine. Beijing: China Financial and Economic Publishing House, 2013.7

[5] shangjin Zhuo. Internet fianncial: in innovation to flourish. Financial Times, 2013.6

[6] Hailong Huang. Internet financial research of based on electronic business platform as the core. Shanghai Finance, 2013 (8):19-23

[7] Allen. Franklin \& Santomero, Anthony M. The theory of financial intermediation. Journal of Banking \&Finance, 1998(21): 1461-1485 